\title{
Геоинформационные карты рельефа Северо-Востока Азии как основа изучения морфологии речных бассейнов
}

\author{
В. Л. Самохвалов, Н.в. Ухов \\ Институт биологических проблем Севера Дальневосточного отделения Российской академии наук, \\ Российская Федераичи \\ (695000, г. Магадан, ул. Портовая, 18)
}

\begin{abstract}
Аннотация: Цель. Создать первые геоинформационные карты горного рельефа Северо-Востока Азии и получить на этой основе морфологические характеристики водосборов, как имеющихся в информационных источниках, так и новых с оценкой точности и уровня корреляционных связей между ними.

Материалы и методы. На их основании сравнительного анализа методов количественной морфометрии рельефа Северо-Востока Азии (аэрофотоснимки, карты, ГИС технологии) установлена перспективность расширения информационной базы с помощью геоинформационных карт. Применение цифровых моделей рельефа наиболее важно для слабо изученных бассейнов малых рек, данные о которых отсутствуют в справочно-фондовых источниках. Выбранная универсальная программа ArcGIS, версии 10.4, дает возможность получить так же принципиально новые параметры водосборных площадей горных рек. В связи с этим цифровая карта с высотными отметками рельефа земной поверхности (SRTM) и послужила исходным материалом для расчета различных морфометрических характеристик водосборов (например, площади и средние высоты водосборов, длину водотоков и т. д.).

Результаты и обсуждение. Статистический анализ величин площадей водосборов, на основе геоинформационных карт (программа ArcGIS, версия 10.4) и растровых аналогов свидетельствует о незначительном их отличии $(-3.9$ to $+3.0 \%)$. Показана перспективность применения цифровых моделей рельефа для получения совершенно новых характеристик бассейнов рек, отсутствующих в известных источниках информации (например, форм, периметров, уклонов средних высот, и. т. д.). Кроме того, на основе статистического анализа дана оценка параметров различных водосборов и их частей (верховье, низовье), например, неоднородность поверхности долин рек и водоразделов. В дополнении указанном выше, установлена тесная, или, в отдельных случаях, функциональная связь между некоторыми характеристиками водосборов (например, уклоны - средние высоты).

Bblводы. Построенные впервые цифровые модели горного рельефа Северо-Востока Азии (программа ArcGIS, версия 10.4) позволили с достаточной точностью вычислить основные морфометрические параметры водосборов рек. Использование цифровых карт с высотами земной поверхности, в частности, SRTM, дали возможность получить принципиально новые, по сравнению с имеющимся уровнем изученности, параметры бассейнов водотоков, необходимые для науки и практики.
\end{abstract}

Ключевые слова: горный рельеф, водосборные бассейны, изученность водосборов, цифровые карты, морфометрический анализ.

Для цитирования: Самохвалов В. Л., Ухов Н.В. Геоинформационные карты рельефа СевероВостока Азии как основа изучения морфологии речных бассейнов // Вестник Воронежского государственного университета. Серия География. Геоэкология, 2020, № 4, с. 14-20. DOI: https://doi.org/10.17308/geo.2020.4/3061

() Самохвалов В.Л., Ухов Н.В., 2020

$₫$ Ухов Николай Васильевич, e-mail: nukhov@mail.ru

Контент доступен под лицензией Creative Commons Attribution 4.0 License. 


\section{ВВЕДЕНИЕ}

Северо-Восток Азии отличается богатством природных и в первую очередь, минеральных ресурсов. Рассматриваемая территория характеризуется чрезвычайно суровым климатом, преимущественно горным рельефом, сложным геолого-географическим строением и практически повсеместным развитием многолетнемерзлых пород. Для такой обширной и слабо изученной территории необходимы новые подходы для расширения и углубления знаний по морфометрии рельефа и водосборов рек. Эта информация необходима для прогноза формирования стока, ландшафтов, многолетнемерзлых пород, а так же связанных с суровым климатом опасных природных процессов.

Данная статья - первая попытка обосновать наиболее приемлемые методы обработки большого массива данных по морфометрии водосборных площадей рек территории и дать сравнительный анализ их основных параметров.

Начиная с конца 60-х годов, основным источником информации по водотокам и их бассейнам были справочник по поверхностным ресурсам вод [1], который в 2010 году оцифрован [3]. Для слабо исследованной обширной территории морфометрические характеристики определены по водотокам протяженностью, преимущественно, более 10 км, что составляет менее $5 \%$ их общего количества (таблица 1). В указанных источниках приведен ограниченный объем морфометрической информации бассейнов рек, т. е. их площадь и протяженность водотоков. Лишь для ручья Контактового, на водосборе которого расположена Колым- ская водно-балансовая станция, получены детальные и исчерпывающие морфометрические данные по водосбору [4].

Для решения практических (например, разработки россыпей в долинах рек), научных (например, вгидробиологи и экологи) задач морфометрии применялся так называемой ручной способ получения не изученных ране водосборных бассейнов картометрическим способом [4].

\section{МЕТОДЫ}

По топографическим картами современным методам аэрокосмической съемки земной поверхности возможно изучение морфометрических параметров водосборов с использованием цифровых моделей рельефа $[5,6,7]$. На основании сравнительного анализа методов количественной морфометрии рельефа Северо-Востока Азии установлена перспективность расширения и углубления информационной базы с помощью цифровых карт. Из рассматриваемых геоинформационных систем наиболее подходит программа ArcGIS версии 10.4, которая позволяет рассчитать наиболее полный перечень параметров речных водосборов. В связи с этим цифровая карта с высотными отметками рельефа земной поверхности (SRTM) и послужила исходным материалом для расчета различных морфометрических характеристик водосборов (например, площади и средние высоты водосборов, длину водотоков и т. д.).

Все анализируемые объекты относятся к бассейнам: Восточно-Сибирского (р. Колыма), Чукотского, а так же отделенных от них главным водоразделом Земли Берингова, Охотского (в пределах

Таблица 1

Общее состояние изученности бассейнов водотоков территории

[Table 1. General state of knowledge of the territory's watercourses basins]

\begin{tabular}{|c|c|c|}
\hline \multirow{2}{*}{$\begin{array}{c}\text { Водотоки морских } \\
\text { бассейнов }\end{array}$} & \multicolumn{2}{|c|}{$\begin{array}{c}\text { Количество бассейнов водотоков } \\
\text { [Number of watercourse basins] }\end{array}$} \\
\cline { 2 - 3 } & $\begin{array}{c}\text { общее } \\
\text { [general] }\end{array}$ & $\begin{array}{c}\text { с измеренной площадью } \\
\text { [with measured area] }\end{array}$ \\
\hline $\begin{array}{c}\text { Восточно-Сибирского } \\
\text { [East Siberian Sea] }\end{array}$ & 8456 & 497 \\
\hline $\begin{array}{c}\text { Чукотского } \\
\text { [Сhukcheе Sea] }\end{array}$ & 1028 & 32 \\
\hline $\begin{array}{c}\text { Берингового } \\
\text { [Chukcheе Sea] }\end{array}$ & 3852 & 78 \\
\hline $\begin{array}{c}\text { Oхотского* } \\
\text { [Sea of Okhotsk]* }\end{array}$ & 1381 & 45 \\
\hline
\end{tabular}

Примечание:* - в пределах Магаданской области.

[Note: * - within the Magadan region] 

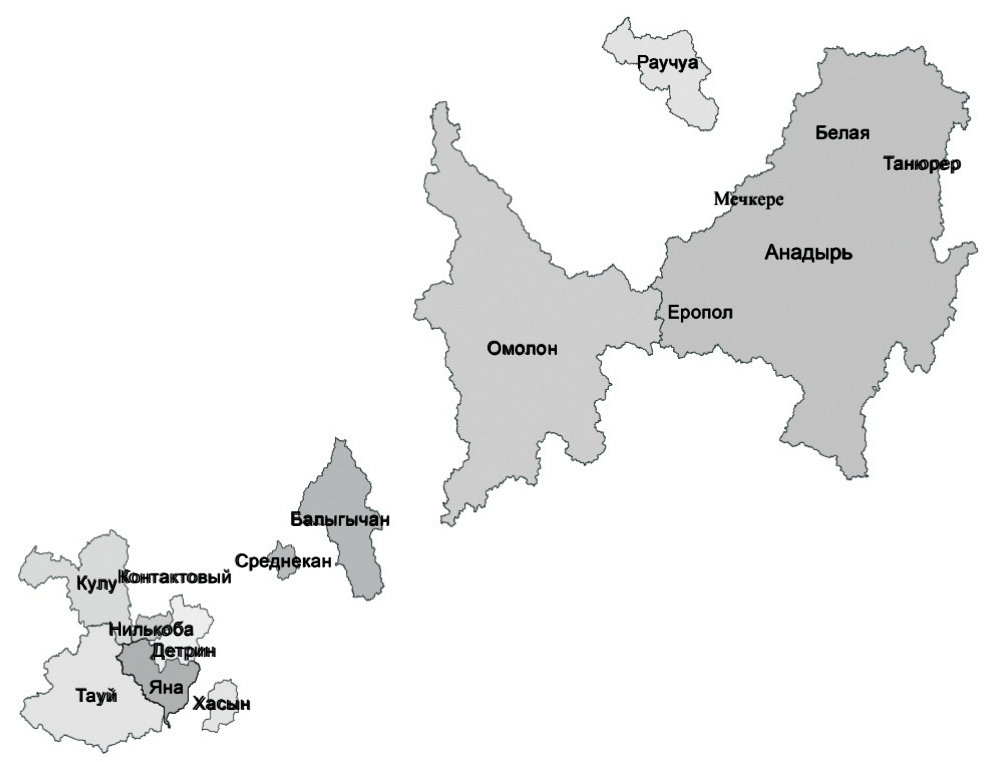

Рuc. Схема расположения рассматриваемых бассейнов водотоков Северо-Востока Азии

[Fig. The layout of the considered watercourses basins in North-East Asia]

Магаданской области) морей. В статье рассмотрены 26 водотоков различной протяженности и площади водосборов (рис.).

\section{ОБСУЖДЕНИЕ РЕЗУЛЬТАТОВ}

Проведен корреляционный анализ величин площадей водосборов водотоков, определенных с использованием ARCGIS со справочными их значениями. Установлено незначительное их различие, причем как в положительную, так и в отрицательную сторону с колебанием в пределах от $-3,9$ до $+3,0 \%$ (таблица 2). Показана перспективность применения цифровых моделей рельефа для получения совершенно новых характеристик бассейнов рек, отсутствующих в известных источниках информации (например, форм, периметров, уклонов средних высот). Достоверной связи между площадью водосбора, определенной с помощью ГИС и по справочнику [1], не наблюдалось как по регионам, так и для всех водотоков в целом. Возможно, что отсутствие зависимости между этими параметрами связаны с трудностями определения местоположения устьевых створов водотоков. Эти ошибки в определении местоположения устьев водотоков могут иметь место не только для приморских рек, но также и для притоков крупных водотоков - реки Колымы и реки Анадырь.

Средние высоты водосборов обследованных водотоков колебались в широких пределах от 200 м над уровнем моря (р. Яровая, р. Колымы в нижнем течении) до 1080 м над уровнем моря у ручья Контактового, в ее верховьях. Максимальные зна- чения этого показателя характерны для водотоков верховий р. Колымы.

Для исследованных бассейнов средние уклоны, как и высоты, изменяются в широких пределах, от 2,20 (p. Танюрер, приток р. Анадырь, нижнее течение), до 14,80 (руч. Контактовый, бассейн верховий р. Колымы). Между уклонами водосборов и их средней высотой для обследованных водотоков прослеживается корреляционная связь. В данном случае величина коэффициента корреляции равная 0,67 показывает лишь о некоторой тенденции увеличения уклона бассейна с возрастанием его высоты, морфологической неоднородности поверхности долин и водоразделов. В тоже время, для некоторых бассейнов территории эта связь более тесная или близкая к функциональной, например, притоков реки Анадырь $(r=0,93)$, в верхнем течении, протекающих в горах, а в нижнем по равнине. Следует отметить, что границы переходов горных частей бассейнов к равнинным участкам довольно четкие.

Периметр водосборного бассейна может служить, например, показателем его формы. Для этого нужно данный параметр сравнивать с длиной окружности круга, равной по площади бассейну водотока. Этот показатель называют коэффициентом развития длины водораздельной линии бассейна. Для обследованных водотоков в наибольшей степени периметр приближается к длине равновеликой по площади окружности для ручья Контактового (135\%), а в наименьшей - для бассейна реки Омолон $(270 \%)$. 
Таблица 2

Характеристики водосборов водотоков, вычисленные на основе высот земной поверхности (SRTM) [Table 2. Watercourse watershed characteristics calculated from ground elevation (SRTM)]

\begin{tabular}{|c|c|c|c|c|c|c|}
\hline \multirow{3}{*}{$\begin{array}{c}\text { Впадение } \\
\text { водотоков } \\
\text { [The confluence of } \\
\text { streams] }\end{array}$} & \multirow[b]{3}{*}{$\begin{array}{c}\text { Водоток } \\
\text { [Watercourse] }\end{array}$} & \multicolumn{5}{|c|}{$\begin{array}{c}\text { Параметры водосборных бассейнов по SRTM } \\
\text { [SRTM drainage basin parameters] }\end{array}$} \\
\hline & & \multirow[b]{2}{*}{$\begin{array}{c}\text { Средняя } \\
\text { высота, м } \\
\text { [average } \\
\text { height, m] }\end{array}$} & \multirow[b]{2}{*}{$\begin{array}{l}\text { периметр, } \\
\text { км } \\
\text { [perimeter, } \\
\text { km] }\end{array}$} & \multirow[b]{2}{*}{$\begin{array}{l}\text { уклон, } \\
\text { градус } \\
\text { [slope, } \\
\text { degree] }\end{array}$} & \multicolumn{2}{|c|}{$\begin{array}{c}\text { Площади } \\
\text { [area] }\end{array}$} \\
\hline & & & & & $\begin{array}{c}\text { абсолютные, } \\
\text { км² }^{2} \\
{[\text { absolute, }} \\
\left.\mathrm{km}^{2}\right]\end{array}$ & $\begin{array}{c}\text { Относительные, } \\
\text { к справочным } \\
\text { данным*), \% } \\
\text { [Relative, to } \\
\text { reference data*, } \\
\% \text { ] }\end{array}$ \\
\hline 1 & 2 & 3 & 4 & 5 & 6 & 7 \\
\hline $\begin{array}{l}\text { p. Колыма } \\
\text { [R. Kolyma] }\end{array}$ & $\begin{array}{l}\text { Кoнтактовый } \\
\text { [Kontaktovy] }\end{array}$ & 1085 & 23 & 14,8 & 23 & $-3,5$ \\
\hline $\begin{array}{l}\text { p. Колыма } \\
\text { [R.Kolyma] }\end{array}$ & $\begin{array}{l}\text { Утиная } \\
\text { [Utinaya] }\end{array}$ & 619 & 95 & 11,1 & 351 & 2,8 \\
\hline $\begin{array}{l}\text { p. Колыма } \\
\text { [R. Kolyma] }\end{array}$ & $\begin{array}{l}\text { Среднекан } \\
\text { [Srednekan] }\end{array}$ & 660 & 209 & 9,5 & 1765 & $-0,3$ \\
\hline $\begin{array}{l}\text { p. Колыма } \\
\text { [R. Kolyma] }\end{array}$ & $\begin{array}{l}\text { Нелькоба } \\
\text { [Nelkoba] }\end{array}$ & 952 & 238 & 8,8 & 2051 & $-3,4$ \\
\hline $\begin{array}{l}\text { p. Колыма } \\
\text { [R. Kolyma] }\end{array}$ & $\begin{array}{l}\text { Яровая } \\
\text { [Yarovaya] }\end{array}$ & 200 & 416 & 2,6 & 4144 & $-0,6$ \\
\hline $\begin{array}{l}\text { p. Колыма } \\
\text { [R. Kolyma] }\end{array}$ & $\begin{array}{l}\text { Детрин } \\
\text { [Detrin] }\end{array}$ & 874 & 473 & 10,2 & 6371 & $-1,2$ \\
\hline $\begin{array}{l}\text { p. Колыма } \\
\text { [R. Kolyma] }\end{array}$ & $\begin{array}{l}\text { Берелёх } \\
\text { [Berelyokh] }\end{array}$ & 1061 & 600 & 7,5 & 9778 & $-0,3$ \\
\hline $\begin{array}{l}\text { p. Колыма } \\
\text { [R. Kolyma] }\end{array}$ & $\begin{array}{l}\text { Кулу } \\
{[\text { Kulu }]}\end{array}$ & 1058 & 910 & 10,1 & 15964 & 2,3 \\
\hline $\begin{array}{l}\text { p. Колыма } \\
\text { [R. Kolyma] }\end{array}$ & $\begin{array}{l}\text { Балыгычан } \\
\text { [Berelyokh] }\end{array}$ & 594 & 893 & 6 & 17483 & $-0,7$ \\
\hline $\begin{array}{l}\text { p. Колыма } \\
\text { [R. Kolyma] }\end{array}$ & $\begin{array}{l}\text { Аян-Юрях } \\
\text { [Ayan- } \\
\text { Yuryakh] }\end{array}$ & 1050 & 974 & 7,8 & 23768 & $-1,4$ \\
\hline $\begin{array}{l}\text { p. Колыма } \\
\text { [R. Kolyma] }\end{array}$ & $\begin{array}{l}\text { Омолон } \\
\text { [Omolon] }\end{array}$ & 590 & 3267 & 6 & 116261 & 2,8 \\
\hline $\begin{array}{l}\text { p. Армань } \\
\text { [R. Kolyma] }\end{array}$ & $\begin{array}{l}\text { Хасын } \\
\text { [Khasyn] }\end{array}$ & 515 & 274 & 9 & 3105 & 0,5 \\
\hline $\begin{array}{l}\text { Охотское море } \\
\text { [Sea of Okhotsk] }\end{array}$ & $\begin{array}{l}\text { Вилига } \\
\text { [Viliga] }\end{array}$ & 684 & 422 & 11,2 & 4511 & 0,5 \\
\hline $\begin{array}{l}\text { Охотское море } \\
\text { [Sea of Okhotsk] }\end{array}$ & $\begin{array}{l}\text { Tахтояма } \\
\text { [Takhtoyama] }\end{array}$ & 753 & 458 & 12,3 & 5095 & $-0,3$ \\
\hline $\begin{array}{l}\text { Охотское море } \\
\text { [Sea of Okhotsk] }\end{array}$ & $\begin{array}{l}\text { Армань } \\
\text { [Arman] }\end{array}$ & 663 & 542 & 10,4 & 7836 & 0,8 \\
\hline $\begin{array}{l}\text { Охотское море } \\
\text { [SeaofOkhotsk] }\end{array}$ & $\begin{array}{l}\text { Яна } \\
\text { [Yana[ }\end{array}$ & 661 & 573 & 4,2 & 8334 & $-3,9$ \\
\hline $\begin{array}{l}\text { Охотское море } \\
\text { [Sea of Okhotsk] }\end{array}$ & $\begin{array}{l}\text { Гижига } \\
\text { [Gizhiga] }\end{array}$ & 429 & 663 & 7,8 & 12173 & 2,2 \\
\hline $\begin{array}{l}\text { p. Тауй } \\
\text { [R. Taui] }\end{array}$ & $\begin{array}{l}\text { Чеёломжа } \\
\text { [Cheyolomzha] }\end{array}$ & 545 & 802 & 8,1 & 12290 & 2,4 \\
\hline $\begin{array}{l}\text { Охотское море } \\
\text { [Sea of Okhotsk] }\end{array}$ & $\begin{array}{l}\text { Тауй } \\
\text { [Taui] }\end{array}$ & 378 & 1069 & 4,5 & 26225 & 1,2 \\
\hline $\begin{array}{l}\text { p. Анадырь } \\
\text { [R. Anadyr] }\end{array}$ & $\begin{array}{l}\text { Мечкерева } \\
\text { [Mechkereva] }\end{array}$ & 541 & 394 & 5,3 & 3722 & 0,3 \\
\hline
\end{tabular}


Продолжение таблищь 2 [Table 2 (continued)]

\begin{tabular}{|c|c|c|c|c|c|c|}
\hline 1 & 2 & 3 & 4 & 5 & 6 & 7 \\
\hline $\begin{array}{l}\text { Восточно- } \\
\text { Сибирское море } \\
\text { [East-Siberian Sea] }\end{array}$ & $\begin{array}{l}\text { Раyчya } \\
\text { [Rauchua] }\end{array}$ & 416 & 873 & 5,2 & 14948 & $-3,0$ \\
\hline $\begin{array}{l}\text { Берингово море } \\
\text { [Bering Sea] }\end{array}$ & $\begin{array}{l}\text { Анадырь } \\
\text { [Anadyr] }\end{array}$ & 369 & 3716 & 4,9 & 195202 & 2,2 \\
\hline $\begin{array}{l}\text { p. Анадырь } \\
\text { [R. Anadyr] }\end{array}$ & $\begin{array}{l}\text { Еропол } \\
\text { [Eropol] }\end{array}$ & 620 & 646 & 7,8 & 10881 & 1,7 \\
\hline $\begin{array}{l}\text { p. Анадырь } \\
\text { [R. Anadyr] }\end{array}$ & $\begin{array}{l}\text { Яблон } \\
\text { [Yablon] }\end{array}$ & 680 & 629 & 8,7 & 9480 & 2,1 \\
\hline $\begin{array}{l}\text { Берингово море } \\
\text { [Bering Sea] }\end{array}$ & $\begin{array}{l}\text { Taнюрер } \\
\text { [Tanyurer] }\end{array}$ & 319 & 1261 & 2,2 & 19069 & 3,0 \\
\hline $\begin{array}{l}\text { p. Анадырь } \\
\text { [R. Anadyr] }\end{array}$ & $\begin{array}{l}\text { Белая } \\
\text { [Belaya] }\end{array}$ & 429 & 1448 & 4,8 & 45532 & 1,8 \\
\hline
\end{tabular}

Примечание: * - Ресурсы....[3].

[Note: * - Resources .... [3]].

\section{ЗАКЛЮЧЕНИЕ}

Данная статья - первая попытка обоснования наиболее приемлемых методов обработки большого массива информации по морфометрии водосборных площадей рек территории с оценкой точности полученных параметров. Опробованная программа ArcGIS версии 10.4 дают возможность построить модели рельефа в формате цифровых карт с высотами земной поверхности, в частности, SRTM, а на ее основе вычислить характеристики водосборных бассейнов.

Для исследованных бассейнов установлено, что средние уклоны, как и высоты, изменяются в широких пределах, от 2,20 (p. Танюрер, приток p. Анадырь, нижнее течение) до 14,80 (руч. Контактовый, бассейн верховий р. Колымы). Между уклонами водосборов и их средней высотой для обследованных водотоков прослеживается корреляционная связь.

Таким образом, дальнейшее развитие геоинформационных технологий позволит получить принципиально новые, по сравнению с имеющимся уровнем изученности, параметры бассейнов водотоков, необходимые для науки и практики.

\section{СПИСОК ЛИТЕРАТУРЫ}

1. Ресурсы поверхностных вод Северо-Восток. Ленинград, Гидрометиздат, 1969, т. 19. 284 с.
2. Руководство по определению гидрографических характеристик картометрическим способом. Ленинград, Гидрометеоиздат, 1986. 92 с.

3. Сомов С. В., Яковенко Л. И. Создание электронной базы по данных справочника Государственного водного кадастра (ГВК) «Гидрологическая изученность». Доступно: http://meteo.ru/component/content/ article/116-trudy-vniigmi/trudy-vniigmi-mtsd-vypusk-1742010-g/384-sozdanie-elektronnoj-bazy-po-dannykhspravochnika-gosudarstvennogo-vodnogo-kadastra-gvkgidrologicheskaya-izuchennost. (дата обращения 4.08.2020)

4. Факторы формирования общего стока мальх горных рек в Субарктике (по материалам Колымской воднобалансовой станции) / Под ред. В.Е. Глотова, Н. В. Ухова. Магадан, СВКНИИ ДВО РАН, 2002. 204 с.

5. Чупикова С. А., Андронайте И.К. Морфометрический и фрактальный анализ водосборного бассейна р. Хурал // Природные ресурсы, среда и общество, № 2(2), 2019, c. 54-60.

6. Jasiewicz J., Stepinski T.F. Geomorphons - a pattern recognition approach to classification and mapping of landforms // Geomorphology, 2013, № 182, pp. 147-156.

7. Yamazaki D., Ikeshima D., Tawatari R., Yamaguchi T., O'Loughlin F. [et al.] A high accuracy map of global terrain elevations // Geophysical Research Letters, 2017 , v. 44, pp. 5844-5853.

Конфликт интересов: Авторы декларируют отсутствие явных и потенциальных конфликтов интересов, связанных с публикацией настоящей статьи.

Поступила в редакциию 20.08.2020 Принята к публикаичи 20.11.2020 


\title{
Geoinformation Maps of the Northeast Asia Relief as a Basis For Studying the River Basins Morphology
}

\author{
V.L. Samokhvalov, N. V. Ukhov $\bowtie$ \\ Institute of Biological Problems of the North, Far Eastern Branch of the Russian Academy of Sciences, \\ Russian Federation \\ (18, Portovaya st., Magadan, 695000)
}

\begin{abstract}
Aim. Creation of the first geoinformation maps of mountainous relief of Northeast Asia and obtaining the morphological characteristics of catchments on this basis, both available in information sources and new ones, with an assessment of the accuracy and level of correlations between them.

Materials and methods. On the basis of comparative analysis of the methods of quantitative morphometry of the Northeast Asia relief (aerial photographs, maps, GIS technologies) the prospects for expanding the information base with the help of geoinformation maps has been established. The use of digital terrain models is most important for poorly studied basins of small rivers, data on which are not available in reference sources. The chosen universal program ArcGIS, version 10.4, makes it possible to obtain entirely new parameters of the catchment areas of mountain rivers. In this regard, the digital map with elevation marks of the earth's surface relief (SRTM) served as a source material for calculating various morphometric characteristics of catchments (for example, areas and average heights of catchments, length of streams, etc.).

Results and discussion. Statistical analysis of catchment areas, based on geoinformation maps (ArcGIS program, version 10.4) and raster analogs, indicates their insignificant difference $(-3.9$ to $+3.0 \%)$. The use of digital elevation models is shown to be promising for obtaining completely new characteristics of river basins that are absent in known information sources (for example, shapes, perimeters, slopes of average heights, etc.). In addition, on the basis of statistical analysis, an assessment of the parameters of various catchments and their parts (upstream, downstream) is given, for example, the heterogeneity of the surface of river valleys and watersheds. In addition, a close, or, in some cases, functional relationship has been established between some characteristics of the catchments (for example, slopes - average heights).

Conclusions. First digital models of mountainous relief in Northeast Asia (ArcGIS, version 10.4), made it possible to calculate the main morphometric parameters of river catchments with sufficient accuracy. The use of digital maps with the heights of the earth's surface, in particular, SRTM, made it possible to obtain entirely new, comparing to the existing level of knowledge, parameters of watercourse basins necessary for science and practice.
\end{abstract}

Key words: mountainous relief, catchment basins, study of catchment basins, digital maps, morphometric analysis.

For citation: Samokhvalov V.L., Ukhov N. V. Geoinformation maps of the Northeast Asia relief as a basis for studying the river basins morphology. Vestnik Voronezskogo gosudarstvennogo universiteta. Seria Geografia. Geoekologia, 2020, No. 4, pp. 14-20. (In Russ.) DOI: https://doi.org/10.17308/geo.2020.4/3061

\section{REFERENCES}

1. Resursy poverkhnostnykh vod Severo-Vostok [Resources of surface waters North-East]. Leningrad, Publ. Gidrometizdat, 1969 , v. 19.284 p. (In Russ.)
2. Rukovodstvo po opredeleniyu gidrograficheskikh kharakteristik kartometricheskim sposobom [Guidelines for the determination of hydrographic characteristics by the cartometric method]. Leningrad, Publ. Gidrometeoizdat, 1986. 92 p. (In Russ.)

(C) Samokhvalov V.L., Ukhov N.V., 2020

\ikolai V. Ukhov, e-mail: nukhov@mail.ru

(i) The content is available under Creative Commons Attribution 4.0 License. 
3. Somov S. V., Yakovenko L. I. Sozdanie elektronnoy bazy po dannykh spravochnika Gosudarstvennogo vodnogo kadastra (GVK) "Gidrologicheskaya izuchennost", [Creation of an electronic database based on the data of the State Water Cadastre (GWC) reference book "Hydrological knowledge"]. (In Russ.) Available: http://meteo.ru/component/content/article/116-trudy-vniigmi/trudy-vniigmimtsd-vypusk-174-2010-g/384-sozdanie-elektronnoj-bazypo-dannykh-spravochnika-gosudarstvennogo-vodnogo-kadastra-gvk-gidrologicheskaya-izuchennost. (accessed 4.08.2020)

4. Faktory formirovaniya obshchego stoka malykh gornykh rek v Subarktike (po materialam Kolymskoy vodnobalansovoy stantsii) [Factors of the formation of the total runoff of small mountain rivers in the Subarctic (based on the materials of the Kolyma water balance station)]. Ed.

Самохвалов Владимир Людвигович

кандидат географических наук, старший научный сотрудник Института биологических проблем Севера Дальневосточного отделения РАН, г. Магадан, Российская Федерация, ORCID: https://orcid.org/0000-0001-7295-8822, e-mail: mokhva@yandex.ru

Ухов Николай Васильевич кандидат геолого-минералогических наук, старший научный сотрудник Института биологических проблем Севера Дальневосточного отделения РАН, г. Магадан, Российская Федерация, e-mail: nukhov@ mail.ru
V.E. Glotov, N. V. Ukhov. Magadan, SVKNII DVO RAN, 2002. 204 p. (In Russ.)

5. Chupikova S.A., Andronayte I. K. Morfometricheskiy i fraktal'nyy analiz vodosbornogo basseyna r. Khural [Morphometric and fractal analysis of the drainage basin of the river. Khural]. Prirodnye resursy, sreda $i$ obshchestvo, 2019, no. 2(2), pp. 54-60. (In Russ.)

6. Jasiewicz J., Stepinski T.F. Geomorphons - a pattern recognition approach to classification and mapping of landforms. Geomorphology, 2013, no. 182, pp. 147-156.

7. Yamazaki D., Ikeshima D., Tawatari R., Yamaguchi T., O'Loughlin F. [et al.] A high accuracy map of global terrain elevations. Geophysical Research Letters, 2017, v. 44, pp. 5844-5853.

Conflict of interest: The authors declare no obvious and potential conflicts of interest related to the publication of this article.

Received: 20.08 .2020

Accepted: 20.11 .2020

Vladimir L. Samokhvalov

Cand. Sci. (Biol.), Senior Researcher of the Institute of Biological Problems of the North of the Far Eastern Branch of the Russian Academy of Sciences, Magadan, Russian Federation, ORCID: https://orcid.org/0000-0001-7295-8822, e-mail: mokhva@yandex.ru

Nikolai V. Ukhov

Cand. Sci. (Geol.-Miner.), Senior Researcher of the Institute of Biological Problems of the North of the Far Eastern Branch of the Russian Academy of Sciences, Magadan, Russian Federation, e-mail: nukhov@mail.ru 